\title{
EXPERIMENTAL STUDY ON DYNAMIC BEHAVIOR OF UNREINFORCED MASONRY WALLS
}

\author{
Luis MOYA ${ }^{1}$, Cesar FAJARDO ${ }^{2}$, Taiki SAITO ${ }^{3}$, Koichi MORITA ${ }^{4}$
}

\begin{abstract}
SUMMARY
Dynamic behavior of unreinforced masonry wall was investigated through a shaking table test in which two specimens were prepared. In order to simulate non-engineering houses of one story, the first specimen consists of a $\mathrm{C}$ shaped structure, whose masonry walls are connected only by their ends. The second specimen was built to idealize an upper story, therefore the $\mathrm{C}$ wall is connected at the top by a rigid diaphragm floor and a weight suspended. The test result show different behavior between each specimen. In the first specimen an out-of-plane failure mode governs and in second specimen a shear failure mode governs.
\end{abstract}

\section{INTRODUCTION}

A fundamental issue to be resolved is mitigating the seismic hazard of unreinforced masonry (URM) walls. This concern is relevant to Peru because residential buildings located in areas with low economic resources are mostly non-engineering houses. Figure 1 illustrates a nonengineering house built with URM walls and without floor diaphragm. And Figure 2 illustrates typical URM exterior walls of a masonry building, which could injure people around the building when it collapses during earthquakes.

Although the most extensive research on URM buildings was developed by ABK Joint Venture $[1,2]$, it was developed based on structural systems used in USA-California like the use of flexible wood diaphragm. However, it is still the primary source for guidelines developed by Federal Emergency Management Agency [3, 4, 5]. The weakest shape of failure in URM walls is the out-of-plane failure and in those tests it consists of horizontal cracks located at the bottom, top and around the middle wall.

An URM building model that includes a floor diaphragm as well as in-plane and out-of-plane wall components was developed by Simsir et al [6]. In that test the in-plane and out-of-plane walls were connected only by the flexible diaphragm and an axial load was applied to the outof-plane walls. Instead of the mid-height horizontal crack observed in ABK research and others, a horizontal crack located around $70 \%$ of the wall height from the base was observed.

\footnotetext{
${ }^{1}$ Master's Candidate, National University of Engineering, Peru, Email: Lmoyah@uni.pe

${ }^{2}$ Master's Candidate, National University of Engineering, Peru, Email: cafg07@hotmail.com

${ }^{3}$ Chief Research Engineer, Building Research Institute, Japan, Email: tsaito@kenken.go.jp

${ }^{4}$ Chief Research Engineer, Building Research Institute, Japan, Email: morita@kenken.go.jp
} 
This paper summarizes a research that was addressing to better understand the interaction between in-plane and out-of-plane walls when they are connected by their ends (continuity at the corners). The research was undertaken into the project "Enhancement of Earthquake and Tsunami Disaster Mitigation Technology" which is an international collaboration between Japan and Peru. The wall test was carried out in the Structural Engineering Laboratory at the Building Research Institute.

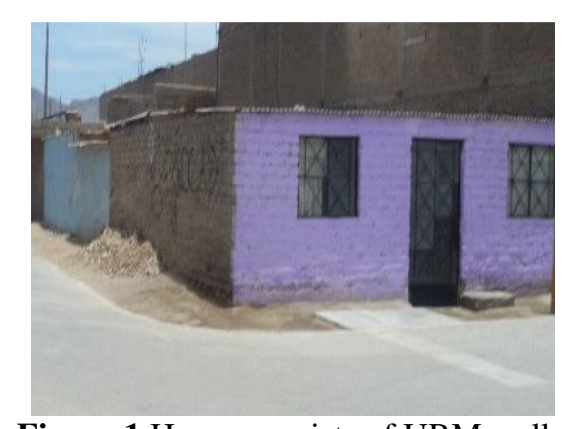

Figure 1 House consists of URM walls

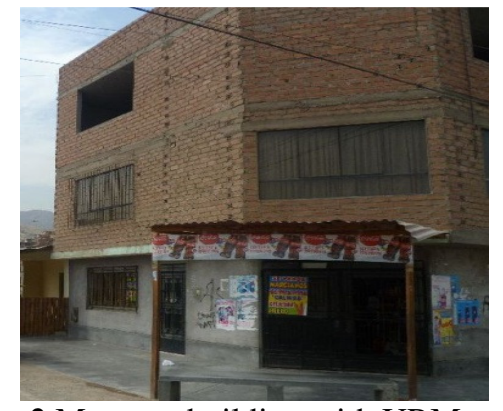

Figure 2 Masonry building with URM external walls

\section{EXPERIMENTAL TEST}

On January 2012 two specimens were constructed on the shaking table of the Structural Engineering Laboratory at Building Research Institute. Figure 3 and 4 illustrate the idealized models which represent an URM wall of a single-story building and an upper level of a multistory building respectively. Each specimen consists of three masonry walls: A, B and C. The ground motion direction was applied perpendicular to the wall $\mathrm{B}$. Therefore, the walls $\mathrm{A}$ and $\mathrm{C}$ will behave in-plane and the wall $\mathrm{B}$ will behave out-of-plane. In the second specimen, a constant axial load of $18 \mathrm{kN}$ approximately was applied by means of a weight suspended over the floor diaphragm.

The wall B has height, width and thickness of $1440 \mathrm{~mm}, 2850 \mathrm{~mm}$ and $100 \mathrm{~mm}$, respectively. The orthogonal walls (A and C) have $1440 \mathrm{~mm}, 1450 \mathrm{~mm}$ and $100 \mathrm{~mm}$ of height, width and thickness, respectively. The above dimensions give a slenderness ratio of 14.4. Solid bricks and type $\mathrm{O}$ mortar were used in the specimen. Masonry prisms of four bricks tall were made when the brick were moist cure for 28 days. The average compressive strength of the masonry prism was found to be 6.09 MPa. Diagonal tension tests according to the ASTM E519 were carried out on $430 \mathrm{~mm}$ x $410 \mathrm{~mm}$ specimens. The average shear strength of the masonry after 28 days was found to be $1.28 \mathrm{MPa}$.

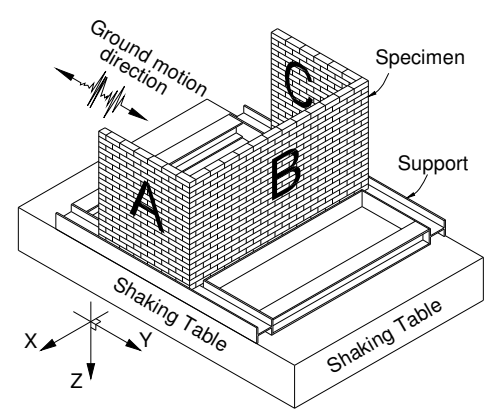

(a)

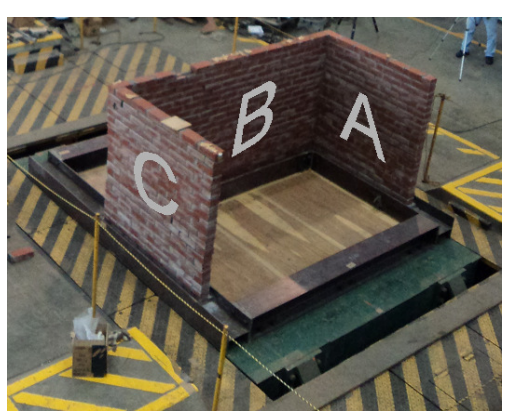

(b)

Figure 3 Specimen 1: (a) Scheme of the test setup (b) Specimen on the shaking table 


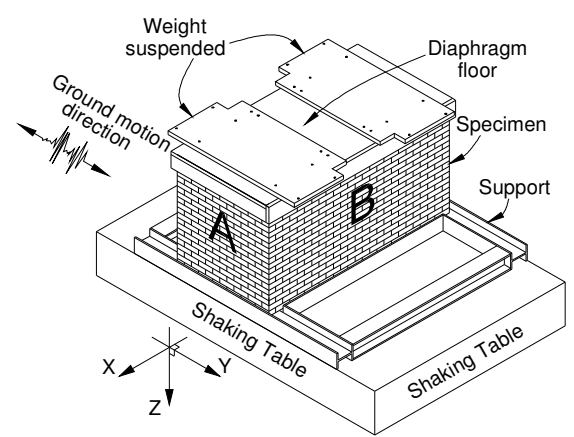

(a)

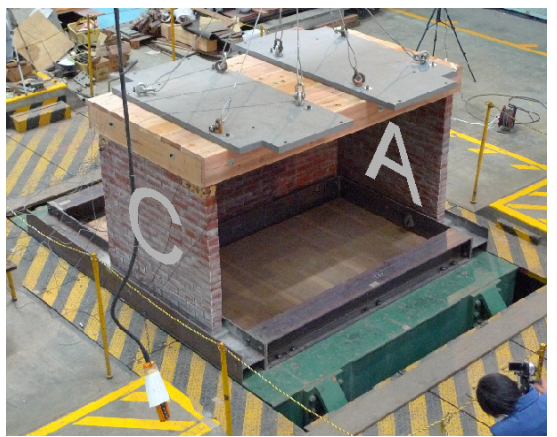

(b)

Figure 4 Specimen 2: (a) Scheme of the test setup (b) Specimen on the shaking table

Fourteen accelerometers, seven pi-gauges and a data acquisition system were used to record the dynamic characteristics of the walls in the specimens. The figure 5 (a) shows the position of the accelerometers. The A00, A05 and A13 accelerometers recorded vibrations in the up-down direction and all the others recorded vibrations in the direction perpendicular to the wall where they are located. Assuming that the wall "B" will fail similar to the shape of failure of a slab (out-of-plane behavior), it was decided to collocate the pi-gauges as illustrated in figure 5 (b). As you can see, most of the accelerometers were placed on the wall $\mathrm{B}$. That is because previous researchers showed the out-of-plane as the weakest mode of failure

Three additional accelerometers were placed over the floor diaphragm, for the second specimen. The accelerometer located at the middle of the diaphragm recorded the acceleration in the same direction of the shaking table and the other two, which were located at the ends, recorded the acceleration in the up and down direction.

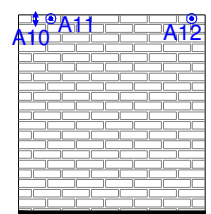

Wall A

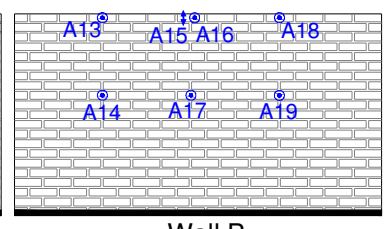

(a)

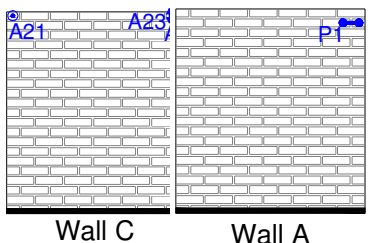

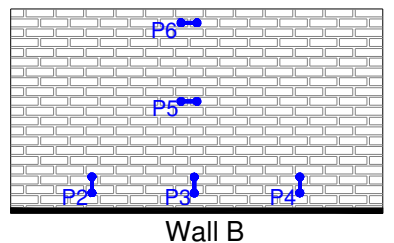

(b)

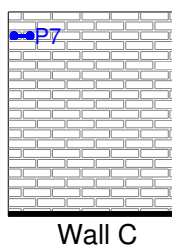

Wall C

Figure 5 Instrumentation for the wall test: (a) accelerometers and (b) pi-gauges

\section{TEST PROCEDURE AND RESULTS}

\section{First Specimen}

A total of twenty unidirectional signals were applied at the base of the first specimen. For each test, the type of signal, the amplitude of the table shake, the peak table acceleration, the maximum measured displacement and acceleration at the top and mid-height of the wall B are given in Table 1. The displacements showed are relative to the base and the accelerations are absolute values.

Two types of signals were applied over the tests: frequency sweep test and frequency random test. Frequency sweep test was useful to monitor the shift of the natural frequency of the wall B. As a result of the damage produced in the specimen during the tests, the natural frequency of the specimen had been decreasing continuously. As shown in Figure 6, which is the record of the 
accelerometer placed at the middle top of the wall $\mathrm{B}$, the natural frequency decreased from an initial value of $19.34 \mathrm{~Hz}$ to $6.29 \mathrm{~Hz}$ by the end of the $19^{\text {th }}$ dynamic test run.

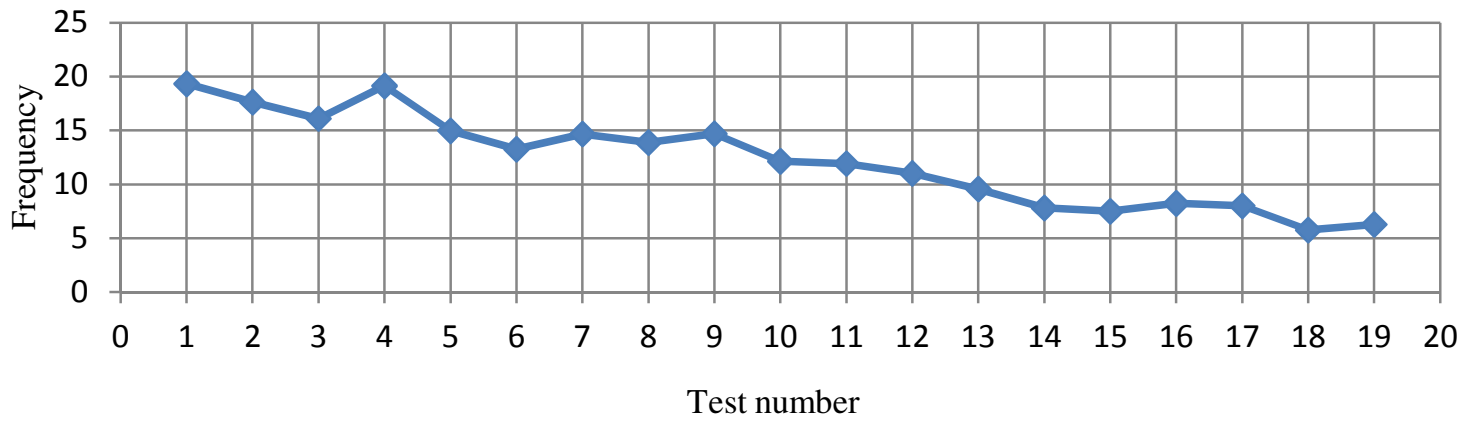

Figure 6 Variation of the natural frequency of the first specimen

Table 1 Shake table runs and recorded peak values for the first specimen

\begin{tabular}{ccccccccc}
\hline \multirow{2}{*}{ Test } & Type & Frequency & Amplitude & Peak Table & \multicolumn{2}{c}{ Displacements } & \multicolumn{2}{c}{ Accelerations $(\mathrm{g})$} \\
\cline { 6 - 8 } & wave & $(\mathrm{hz})$ & $(\mathrm{mm})$ & Acceleration $(\mathrm{g})$ & Top & Mid-height & Top & Mid-height \\
\hline 1 & sweep & $0.8-20$ & 0.5 & 0.01 & 0.13 & 0.09 & 0.05 & 0.03 \\
2 & sweep & $0.8-20$ & 0.5 & 0.43 & 2.74 & 1.75 & 2.15 & 1.56 \\
3 & sweep & $0.8-20$ & 0.5 & 0.40 & 2.31 & 1.83 & 2.02 & 1.37 \\
4 & random & $5-20$ & 0.5 & 0.02 & 0.21 & 0.15 & 0.11 & 0.08 \\
5 & random & $5-20$ & 10.0 & 0.67 & 3.34 & 2.92 & 3.10 & 2.18 \\
6 & random & $12-20$ & 5.0 & 0.28 & 1.21 & 0.77 & 0.88 & 0.45 \\
7 & random & $12-20$ & 5.0 & 0.24 & 1.33 & 0.76 & 1.06 & 0.47 \\
8 & random & $12-20$ & 10.0 & 0.67 & 2.75 & 1.7 & 2.31 & 0.88 \\
9 & random & $12-20$ & 15.0 & 1.21 & 4.93 & 2.56 & 5.01 & 1.41 \\
10 & random & $10-15$ & 5.0 & 0.17 & 1.58 & 0.62 & 1.18 & 0.23 \\
11 & random & $10-15$ & 10.0 & 0.39 & 3.16 & 1.41 & 1.96 & 0.55 \\
12 & random & $10-15$ & 15.0 & 0.66 & 7.46 & 2.78 & 3.33 & 0.97 \\
13 & sweep & $0.8-20$ & 0.5 & 0.25 & 3.12 & 1.03 & 1.47 & 0.33 \\
14 & random & $5-15$ & 10.0 & 0.70 & 4.91 & 2.01 & 2.69 & 1.17 \\
15 & random & $5-15$ & 20.0 & 1.01 & 8.39 & 4.12 & 5.00 & 1.50 \\
16 & random & $5-10$ & 20.0 & 0.45 & 7.68 & 2.93 & 2.45 & 0.91 \\
17 & random & $5-10$ & 30.0 & 0.60 & 9.39 & 3.38 & 3.24 & 1.22 \\
18 & random & $5-10$ & 40.0 & 0.73 & 12.94 & 5.17 & 4.89 & 1.69 \\
19 & random & $5-10$ & 50.0 & 1.18 & 11.49 & 6.18 & 5.73 & 2.59 \\
20 & random & $3-8$ & 70.0 & --- & --- & --- & --- & --- \\
\hline
\end{tabular}

Although most the cracks were observed over the out-of-plane wall component, the crack patterns before the failure was different than previous investigations. As shown in Figure 7, the first cracks were observed after the $5^{\text {th }}$ test and it was located at the middle top of the wall B and also at the top of the corners. After the $9^{\text {th }}$ test the initial cracks become wider and a diagonal crack appear over the wall B. This diagonal crack has not been seen in previous research. Another diagonal crack appears in the same wall after the $19^{\text {th }}$ test. Besides, the cracks located at the upper corners became larger and they reached the half-height of the wall. Finally, when the connection between in-plane and out-of-plane walls were partially lost, a horizontal crack formed at the middle of the wall, which corresponds to the collapse of the specimen (see Figure $8)$. 


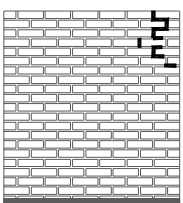

Wall A

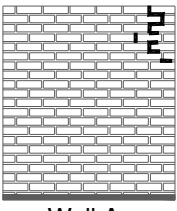

Wall A

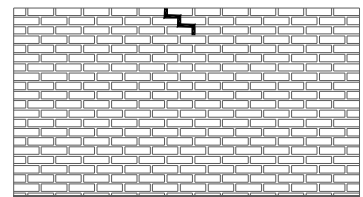

Wall B

After Test 05

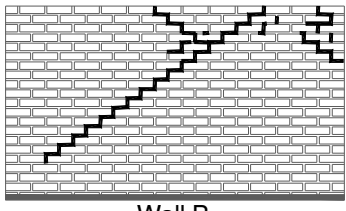

Wall B

After test 13

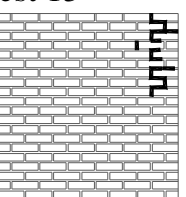

Wall A

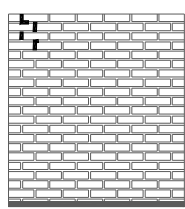

Wall C

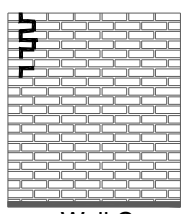

Wall C

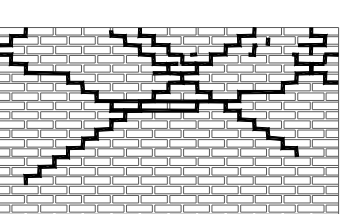

Wall B

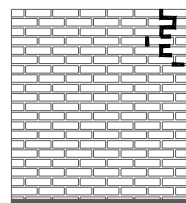

Wall A

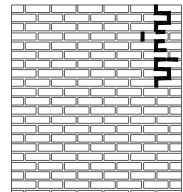

Wall A

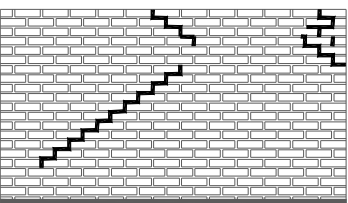

Wall B

After test 09

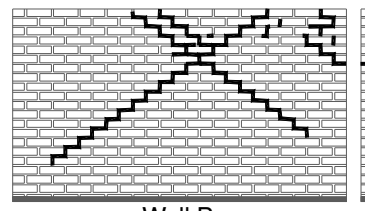

Wall B

After test 19

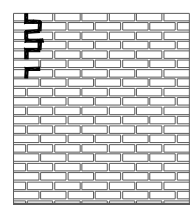

Wall C

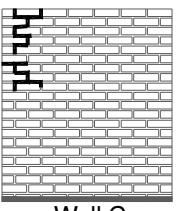

Wall C

After test 20

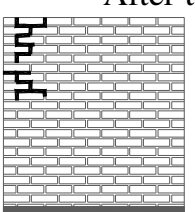

Wall C

Figure 7 Crack patterns developed in the first specimen
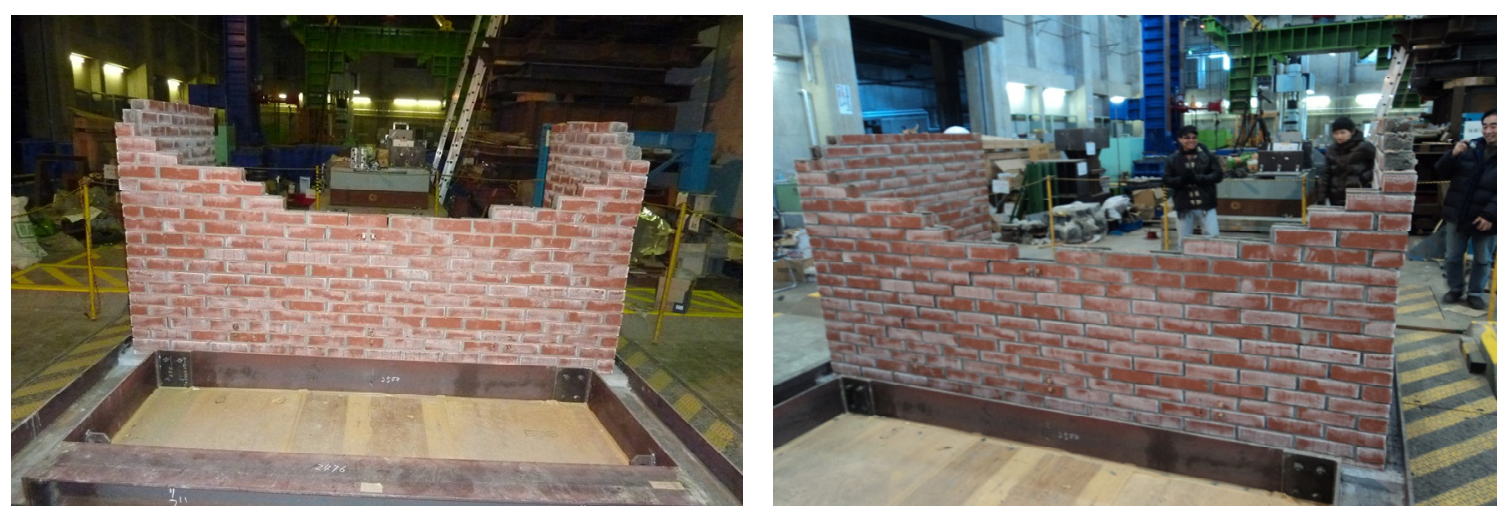

Figure 8 Shape of failure of the second specimen

\section{Second Specimen}

A total of 23 unidirectional signals were applied at the base. The Table 2 shows the type of signal, the amplitude of the table shake, the peak table acceleration, the maximum measured displacement and acceleration at the top and mid-height for the second specimen. However, while the values of displacement and acceleration at the top are from the rigid diaphragm, the values at the mid-height are from the wall $\mathrm{B}$.

There are no information of the maximum values of displacement and acceleration for the tests 21 and 22 because the accelerometers were removed before. Three types of signals were applied over the tests: frequency sweep test, frequency random test and Kobe earthquake. As mentioned above, frequency sweep test was used to find out the shift of the natural frequency of the specimen. 
Table 2 Shake table runs and recorded peak values for the second specimen

\begin{tabular}{ccccccccc}
\hline \multirow{2}{*}{ Test } & Type & Frequency & Amplitude & Peak Table & \multicolumn{2}{c}{ Displacements $(\mathrm{mm})$} & \multicolumn{2}{c}{ Accelerations $(\mathrm{g})$} \\
\cline { 6 - 9 } & wave & $(\mathrm{hz})$ & $(\mathrm{mm})$ & Acceleration $(\mathrm{g})$ & Top & Mid-height & Top & Mid-height \\
\hline 1 & sweep & $0.8-20$ & 0.5 & 0.15 & 0.91 & 0.48 & 0.33 & 0.23 \\
2 & sweep & $0.8-20$ & 0.5 & 0.15 & 1.37 & 0.21 & 0.33 & 0.24 \\
3 & random & $5-20$ & 0.5 & 0.02 & 0.14 & 0.10 & 0.04 & 0.03 \\
4 & random & $10-15$ & 0.5 & 0.01 & 0.11 & 0.13 & 0.02 & 0.02 \\
5 & random & $10-15$ & 2.0 & 0.04 & 0.27 & 0.10 & 0.10 & 0.07 \\
6 & random & $10-15$ & 10.0 & 0.23 & 1.31 & 0.42 & 0.59 & 0.49 \\
7 & random & $10-15$ & 15.0 & 0.52 & 1.92 & 1.17 & 0.94 & 1.13 \\
8 & random & $10-15$ & 15.0 & 0.90 & 2.06 & 1.45 & 0.98 & 2.89 \\
9 & random & $12-15$ & 20.0 & 0.78 & 3.38 & 1.36 & 0.90 & 2.25 \\
10 & Kobe earthquake & --- & $0.2^{*}$ & 0.19 & 13.87 & 0.13 & 0.20 & 0.20 \\
11 & random & $12-15$ & 20.0 & 1.13 & 2.66 & 1.44 & 1.16 & 2.72 \\
12 & sweep & $0.8-20$ & 0.5 & 0.17 & 0.97 & 0.29 & 0.33 & 0.49 \\
13 & random & $5-15$ & 30.0 & 1.35 & 5.27 & 2.38 & 1.14 & 4.19 \\
14 & random & $5-15$ & 30.0 & 1.44 & 4.25 & 2.99 & 1.09 & 4.32 \\
15 & random & $5-15$ & 30.0 & 1.82 & 4.20 & 5.45 & 0.96 & 3.65 \\
16 & sweep & $0.8-20$ & 0.5 & 0.20 & 1.18 & 0.86 & 0.22 & 0.43 \\
17 & random & $5-15$ & 30.0 & 1.52 & 4.70 & 6.25 & 1.08 & 3.96 \\
18 & random & $5-15$ & 40.0 & 1.97 & 5.32 & 9.04 & 1.17 & 4.75 \\
19 & random & $5-15$ & 40.0 & 2.11 & 4.87 & 6.34 & 0.89 & 4.73 \\
20 & random & $5-15$ & 40.0 & 2.05 & 5.24 & 8.18 & 1.10 & 4.96 \\
21 & random & $5-10$ & 50.0 & --- & --- & --- & --- & --- \\
22 & Kobe earthquake & --- & $0.5 *$ & --- & --- & --- & --- & --- \\
\hline
\end{tabular}

*These values represent the fraction of the Kobe earthquake that is applied in the test

This time most of the cracks were developed over the in-plane walls. It seems that the axial load produced by the weight suspended at the top had improved the flexural strength of the wall B. Furthermore, a kind of confinement is provided by the floor diaphragm and the roof. As shown in Figure 9, at the beginning the cracks patterns developed over the in-plane walls components were totally different between them. After the $15^{\text {th }}$ test, a bed-joint sliding on a horizontal plane located at the top was developed in the wall A; on the other hand, a sliding on a stair-stepped diagonal crack was developed in the wall C. Due to the difference of behavior between the inplane wall components, torsional movements was developed in the specimen. After the 18th test, diagonal cracks, which began in the in-plane walls and end up on the wall $\mathrm{B}$, were developed because the torsional behavior. Finally, the shape of failure is illustrated in Figure 10.



Wall A

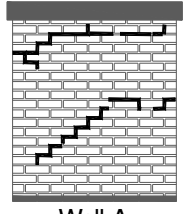

Wall A

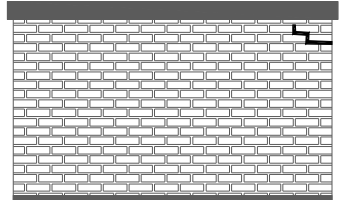

Wall B After $12^{\text {th }}$ test

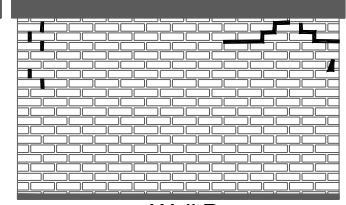

Wall B

After $16^{\text {th }}$ test

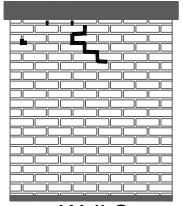

Wall C

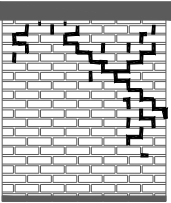

Wall C

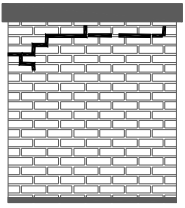

Wall $\mathrm{A}$

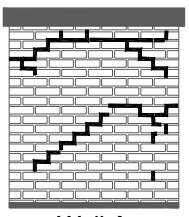

Wall A

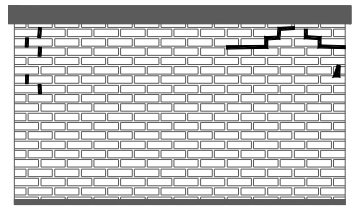

Wall B

After $15^{\text {th }}$ test

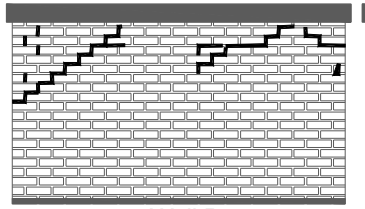

Wall B

After $18^{\text {th }}$ test



Wall C

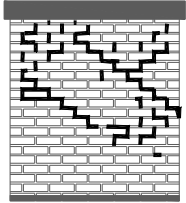

Wall C

Figure 9 Crack patterns developed in the second specimen 


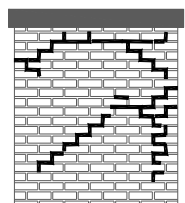

Wall A

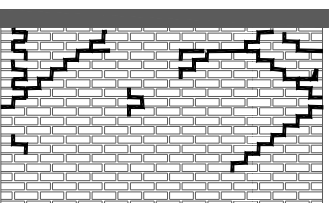

Wall B

After $20^{\text {th }}$ test

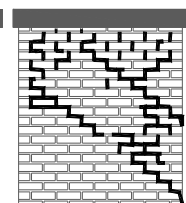

Wall C

Figure 9 Crack patterns developed in the second specimen (continuation)

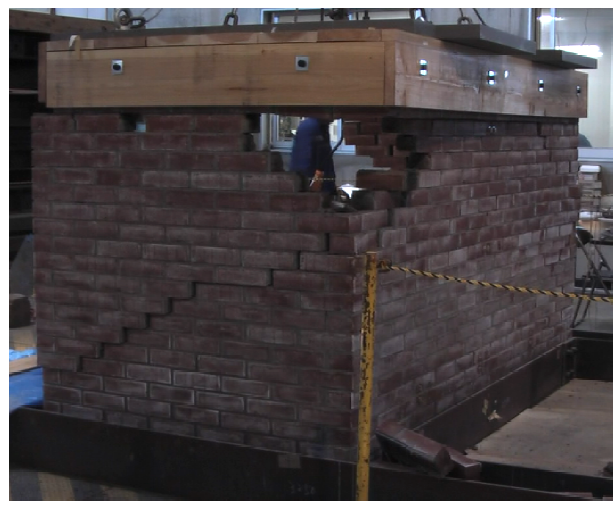

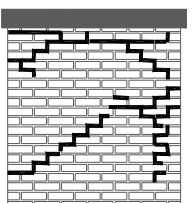

Wall A

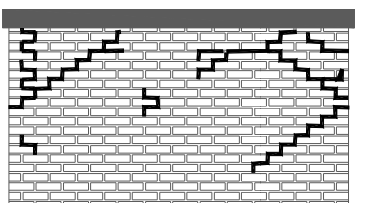

Wall B

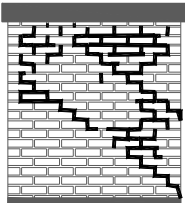

Wall C

After $21^{\text {st }}$ test

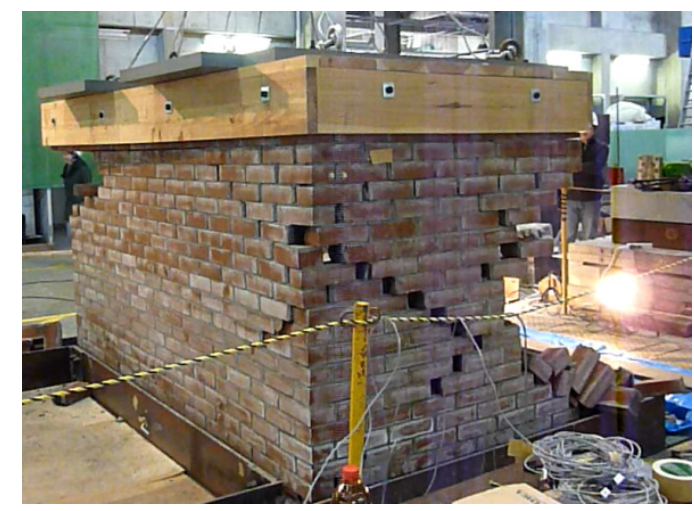

Figure 10 Shape of failure of the second specimen

The change of the natural frequency can be used as a trace of the damage produced in the specimen. The figure 11 illustrates how the natural frequency of the accelerations recorded over the diaphragm had been reducing. However, the natural frequency recorded at the middle-height of the wall B had not been reducing significantly.

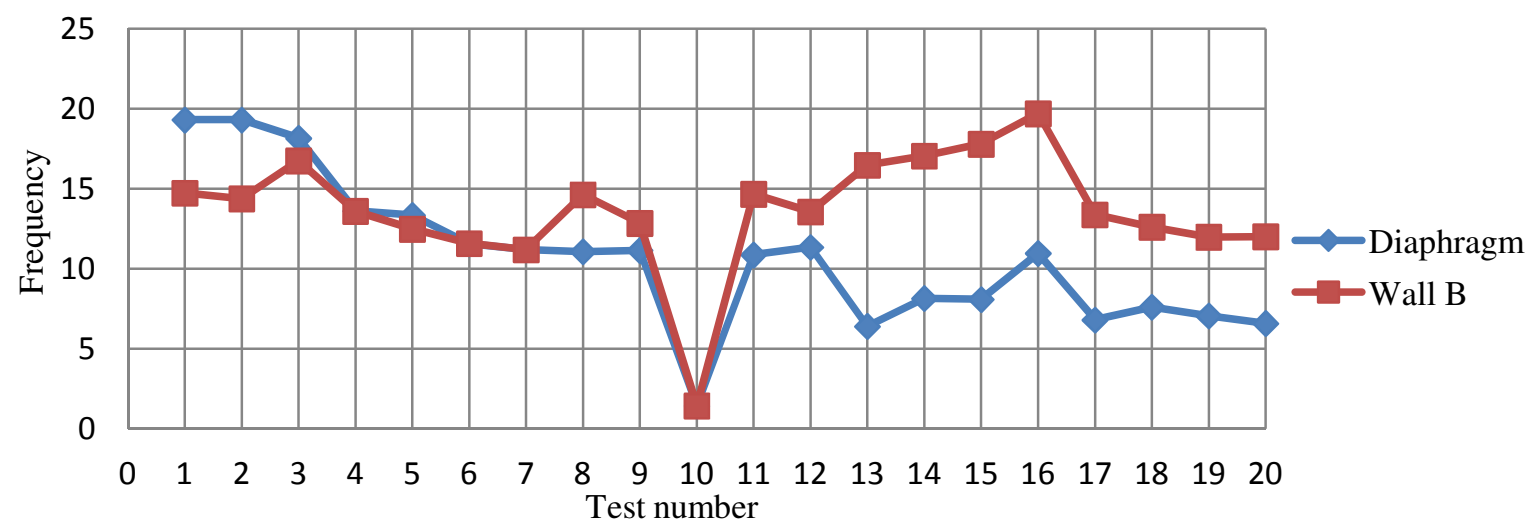

Figure 11 Variation of the natural frequency of the second specimen 


\section{CONCLUSIONS}

The interaction between in-plane and out-of-plane components of an URM wall when they are connected by their ends (corners) has been studied. For this reason, two specimens were tested through a shaking table. The shape of failure of the first specimen, which simulates a singlestory building, was out-of-plane. However, at the beginning the crack patterns were different than previous research due to the influence of the in-plane walls.

It was expected that the shape of failure in both specimens was out-of-plane. Nevertheless, most of the damage in the second specimen was observed on the in-plane walls. The floor diaphragm and the axial load produced by the weight suspended at the top had enhanced the stability of the out-of-plane wall component.

As happened in the second specimen, the possibility of different modes of behavior in the inplane walls components of a building could produce torsional movements. Besides, the URM walls have several shear behavior modes like wall-pier rocking, bed-joint sliding, spandrel-joint sliding, rocking/toe crushing, etc.

Almost all the cracks observed were located in the mortar. It means, the brick units had not been broken. Therefore, analytical models based on simulations of rigid body dynamics could give us a good estimate of the dynamic behavior of URM buildings.

\section{ACKNOWLEDGEMENT}

This study was supported by the research project on earthquake and tsunami disaster mitigation in Peru under the framework of "Science and Technology Research Partnership for Sustainable Development (SATREPS)," by Japan Science and Technology Agency (JST) and Japan International Cooperation Agency (JICA).

\section{REFERENCES}

1. ABK. "Methodology for Seismic Hazard in Existing Unreinforced Masonry Buildings: Wall Testing, Out-of-Plane, Topical Report 04”. ABK Joint Venture, California, December 1981.

2. ABK. "Methodology for Seismic Hazard in Existing Unreinforced Masonry Buildings: The Methodology, Topical Report 08". ABK Joint Venture, California, January 1984.

3. FEMA 306. "Evaluation of Earthquake Damaged Concrete and Masonry Wall Buildings, Basic Procedures Manual". Federal Emergency Management Agency, Washington, D.C., 1999.

4. FEMA 307. "Evaluation of Earthquake Damaged Concrete and Masonry Wall Buildings, Technical Resources". Federal Emergency Management Agency, Washington, D.C., 1999.

5. FEMA 356. "Prestandard and Commentary for the Seismic Rehabilitation of Building". Federal Emergency Management Agency, Washington, D.C., 2000.

6. Simsir CC, Aschheim MA, Abrams DP. "Out-of-Plane Dynamic Response of Unreinforced Masonry Bearing Walls Attached to Flexible Diaphragms". $13^{\text {th }}$ World Conference on Earthquake Engineering, Vancouver, B.C., 2004. 